\title{
ICTs and the concept and practice of internationalisation of higher education
}

\section{Marie Gottlieb}

M.Sc. in IT

Head of Interaction and Learning Unit, IT University of Copenhagen

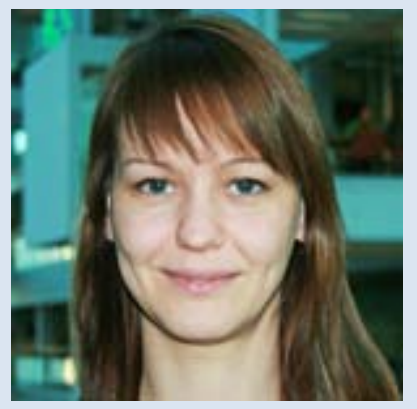

\section{Kathrine Dalgaard}

\section{Skovdal}

M.Sc (econ), CEMS Master in International Management

Global project manager, Interaction and Learning Unit, IT University of Copenhagen

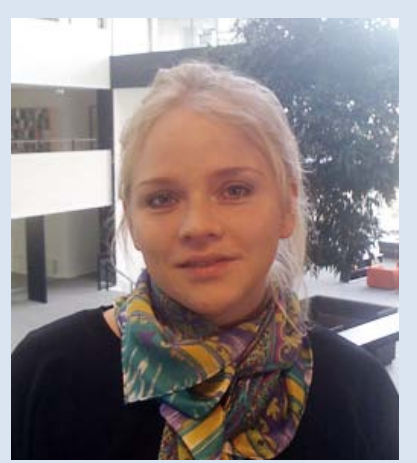




\section{Abstract}

In this article, we will discuss the potential of ICTs in terms of developing the concept and practice of internationalisation of higher education. Based on a number of Danish and international cases, it will be argued that ICTs are being used as tools in the process of developing the concept and practice of internationalisation of higher education. Why this is not happening to a broader extent is discussed and it is suggested that a clear, strategic anchoring of such efforts, including the proper support services, the participation and ownership of faculty, staff and students, and clear financial prospects may be necessary in order to successfully apply ICTs for internationalisation purposes on a broader scale. Finally, it is highlighted that more research, studies and documentation of practice in this area, not least in a Danish setting, would be beneficial to develop and broaden the concept and practice of internationalisation.

\section{Introduction}

The internationalisation of higher education is a topic that has been the subject of quite some interest and focus in recent years, internationally as well as in Denmark. For economic, political, academic, social, and cultural reasons, higher education institutions engage in an increasing multitude of international activities (Knight, 2008, ch. 2). Simultaneously, new Information and Communication Technologies (ICTs) ${ }^{1}$ have emerged and become widely used in society and within organisations for a variety of purposes. The link between the internationalisation of higher education and the use of ICTs is not well established, and apart from a number of assumptions, research and studies of the use of ICTs in relation to the internationalisation of higher education appear to be few and far between. In this article, we will discuss the potential of ICTs in terms of developing the concept and practice of internationalisation of higher education. It should be noted that within institutions of higher education, a large part of the discussion of the use of ICTs has focused on the learning context - often referred to as elearning2. In this paper ICTs are viewed broadly both as supporting/ enhancing learning processes, but also as the underlying framework for learning in an international setting - as enablers of cross-border planning

\footnotetext{
${ }^{1}$ For the purpose of this article, we propose the following definition of the concept: "ICTS stand for information and communication technologies and are defined, for the purposes of this primer, as a "diverse set of technological tools and resources used to communicate, and to create, disseminate, store, and manage information." These technologies include computers, the Internet, broadcasting technologies (radio and television), and telephony." (Tinio 2003, Definition of Terms).

2 For the purpose of this article, we propose the following definition: "Although most commonly associated with higher education and corporate training, e-learning encompasses learning at all levels, both formal and non-formal, that uses an information network - the Internet, an intranet (LAN) or extranet (WAN) - whether wholly or in part, for course delivery, interaction, evaluation and/or facilitation. Others prefer the term online learning. Web-based learning is a subset of e-learning and refers to learning using an Internet browser (such as Firefox or Internet Explorer)." (Tinio 2003, Definition of Terms).
} 
and administrative processes as well as time/location independent communication etc.

Based on a number of Danish and international cases, it will be argued that ICTs are indeed being used as tools in the process of developing the concept and practice of internationalisation. Why this is apparently not happening to a broader extent is discussed and it is suggested that a clear strategic anchoring of such efforts, including the proper support services, the participation and ownership of faculty, staff and students, and clear financial prospects may be necessary in order to successfully apply ICTs for internationalisation purposes on a broader scale. Finally, it is highlighted that more research, studies and documentation of practice in this area, not least in a Danish setting, would be beneficial to develop and broaden the concept and practice of internationalisation.

\section{Method}

The topic will be explored by first looking at the area of the internationalisation of higher education, focusing on how it is currently developing internationally and in the Danish setting according to relevant literature. This section draws to some extent on Jane Knight's book "Higher Education in Turmoil: The Changing World of Internationalization" (Knight 2008), since it is essentially a review of current literature on the subject of internationalisation, showing overall trends and development patterns. But also a variety of other sources are used, particularly to show the development in Denmark. This general section on internationalisation will be followed by a number of case examples from Danish and international universities, selected to show both the width of initiatives in general and various uses of ICTs in internationalisation activities. It is the objective of the cases to make the picture of current internationalisation practices more concrete and tangible to the reader, and to show examples of how ICTs are being used for this purpose. Moving on from this section, we will discuss the role of ICTs in internationalisation initiatives and what appears to be relevant success criteria in that respect. This will be done by drawing on relevant literature and the case examples presented in the previous section mixed with practical experience reported from The University of Copenhagen's Faculty of Life Sciences (LIFE) as well as from recent working experiences of the authors of this paper from the IT University of Copenhagen (ITU). We will conclude by summing up the main discussion of the paper.

It is the overall intention of the article to be of inspiration to both internationalisation and e-learning strategists and practitioners in higher education, particularly in a Danish context, and cases and literature have been chosen for this purpose. It is not the intention to prove any objective causality between ICTs and the internationalisation of higher education, 
nor is it the intention to show any one correct way of merging the two areas. In our perception, it must be up to the individual institutions to determine if and how an internationalisation practice and strategy may be developed and broadened by the use of ICTs.

\title{
Discussion
}

Concept and practice of the internationalisation of higher education The concept. The internationalisation of higher education is a concept that is widely used by both scholars and practitioners worldwide, but not necessarily with the same meaning. As Jane Knight explains:

\begin{abstract}
"While it is encouraging to see increased attention and use of "internationalization", there is a great deal of confusion about what it means. For some people, it means a series of international activities such as academic mobility for students and teachers; international linkages, partnerships, and projects; new international academic programs and research initiatives. For others it means delivering education to other countries using a variety of face-to-face and distance techniques and such new types of arrangements as branch campuses or franchises. To many, it means including an international, intercultural, and/or global dimension in the curriculum and teaching learning process. Still others see international development projects or, alternatively, the increasing emphasis on trade in higher education as internationalization."
\end{abstract}

(Knight 2008: 1)

Knight suggests a broad definition that may encompass all of the above issues:

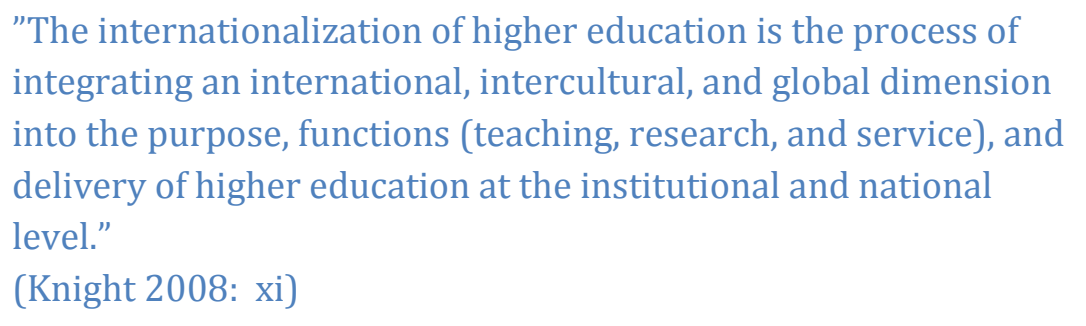

In this article, we will draw on this broad definition and further explore some of the tendencies in the internationalisation concept and practice as they are developing at the moment.

The Danish setting. In Denmark, the internationalisation agenda has focused to a large degree on mobility - attracting international students and researchers and encouraging Danish students and increasingly also researchers to go abroad. This focus has been influenced by several 
factors; first and foremost the Bologna process by which the European countries are trying to standardise the education systems to facilitate an easier mobility of students and researchers among countries (Styrelsen for Internationale Uddannelser 2010). As part of this process, the European countries have agreed to live up to certain criteria related to quality insurance, transparency and mutual recognition of qualifications within Europe. Through the ERASMUS programme and various other exchange programmes, student mobility within and beyond Europe has been facilitated. These various EU and Danish initiatives have meant a significant increase in both incoming and outgoing student mobility since 2000/2001, as Danish universities received 15,265 international students and sent 8,272 Danish students abroad in 2007/2008 (Cirius 2009: 11).

A new development. In recent years a new development in the internationalisation of higher education has been visible, globally and to a certain degree also in Denmark: a move towards a broader definition and practice of internationalisation, one that moves beyond student-centred mobility and into for example strategic alliances between and among institutions, joint development of education programmes and activities, delivering education to other countries by various strategies, etc. These kinds of activities are not new inventions, but the focus they receive from various players and the number and variations of initiatives are increasing (Knight, 2008: Ch. 3).

Using the term crossborder education, Jane Knight (2008: ch. 6) explores this new development. The term highlights the fact that it is no longer only the movement of people that characterises internationalisation of higher education; it is also the movement of programmes, providers, knowledge, ideas, projects, values, curriculums, and services across national boundaries. She points out that

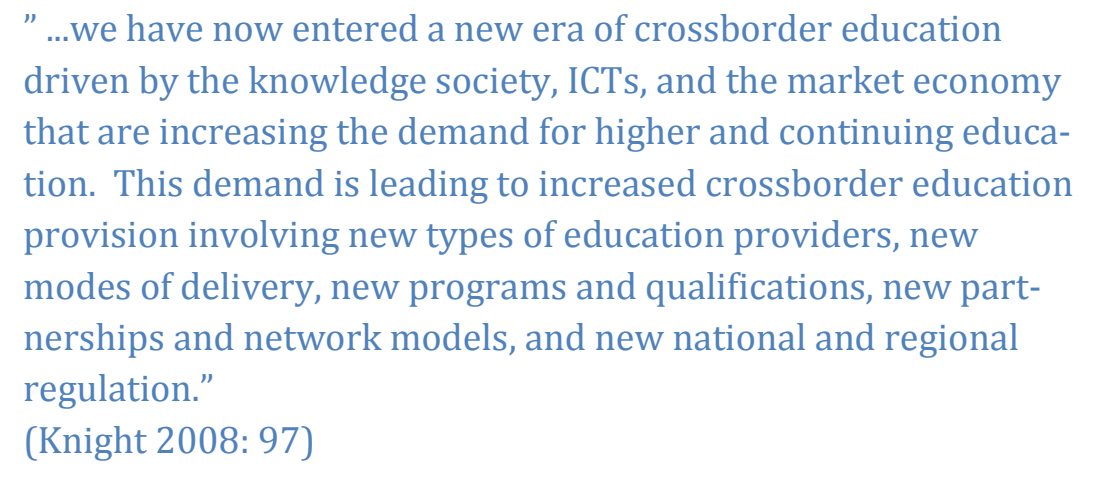

She groups the various mobility categories into four overall categories, namely people, programmes, providers and projects. We shall use these categories to give an overview of the development, although with no illusion of exhausting the topic: 
The movement of people is not a new thing, but the numbers, types and ways in which people move in the sector of higher education are developing and increasing. Thus, students, researchers, experts, etc. do semesters, years, full degrees, field research, internships, sabbaticals and many more activities abroad (Knight 2008: 99).

Today, also programmes are increasingly mobile, meaning that programmes are offered by a country A provider to a country B receiver, the models for this ranging from close collaborations between country $\mathrm{A}$ and $\mathrm{B}$ institutions to entirely independent initiatives by the country A provider. Worth noticing in this category is the possibility for providers to use distance modes of delivery, i.e. students study online and nobody necessarily moves physically (Knight 2008: 100).

Providers have also become mobile. More and more education providers establish a physical or virtual presence in receiving countries. The range again is from setting up an actual satellite campus, merging with local providers, and/or establishing a virtual campus (Knight 2008: 100).

A final category of mobility is projects, which is basically a hotchpotch for a vast number of smaller collaborations at various institutional levels, such as joint curriculum development, research, benchmarking, e-learning platforms, professional development, and many more (Knight 2008: 100-101).

An interesting aspect of the development towards a broader and more encompassing definition and practice of internationalisation to some extent becomes visible in the above categories, namely the notion of virtual mobility. The term illustrates that mobility no longer requires you to necessarily move physically, but can also entail the participation and collaboration in online forums (using various IT platforms, tools, etc.) with people from other countries, cultures, and backgrounds. The concept is used by various sources, but a good introduction to the concept is given by the Movinter Project (2010a). The Movinter Project consists of researchers and other stakeholders from Europe and Latin America who in unison are doing research on various aspects of the concept of virtual mobility:

"The project aims to contribute to increase cooperation and
structural links among Higher Education Institutions (HEI) of
Europe and Latin America through an in-depth exploration of the
potential of ICT - and particularly Virtual Mobility - to inter-
nationalise curricula and learning experiences."
(Movinter Project 2010a)

"MOVINTER's concept of virtual mobility is based on joint design of curricula by HEIs of different countries; international teaching 


\begin{abstract}
teams, cooperating in the design, implementtation and evaluation of courses; clusters of students from different countries who study mainly in their local (chosen) university with their fellow students and without going abroad for long periods of time to study; high interaction, through ICT, among the groups of students based in different countries, to discuss diversity depending on national/local/contextual elements; choice of subjects that justifies the contribution from different countries: especially social sciences, law, economics, but practically any subject in which comparisons from different national contexts may enhance the value of curricula and prepare students for an international social, economical and professional environment; wherever possible, joint titles based on a long term confidence relationship among the participating HEIs, built on previous research and teaching cooperation."

(Movinter Project 2010b)
\end{abstract}

As such, the term need not be confined to include only students, but could just as well include the virtual interaction of researchers or administrative staff. Furthermore, virtual mobility need not be a substitute for physical mobility, but can be a strong supplement. Firstly, in the sense that many students, scholars and even administrative staff at universities, who for whatever reason are not willing, able or allowed to engage in physical mobility, can access a somewhat similar international experience through virtual mobility. Not all elements are the same, but they will engage in intercultural interaction and need to deal with all the related complexities and thus gain relevant competences and experiences. Secondly, it can be a supplement in the sense that virtual mobility may inspire students and staff who would otherwise not engage in traditional mobility, to go abroad by making the foreign seem much closer, more familiar and more approachable by making it a part of the person's everyday life to engage in virtual interaction with peers and experts from all over the world. Finally, virtual mobility may have its own learning purpose, which cannot be fulfilled by physical mobility, namely that of teaching the participants to collaborate in a virtual space without the possibility of meeting physically. This is indeed a stated objective of many of the study programmes involving virtual mobility, as will be seen in the cases referenced below.

To sum up, the models for crossborder education are many, and the mix of virtual and physical mobility is an important part of this picture. Naturally, this is not a full overview of recent developments in the internationallisation of higher education. It is merely a few carefully selected tendencies visible in the current development of the internationalisation concept and practice, which seem to be particularly relevant when considering the use of ICTs in the area. For the purpose of this article, suffice it to say that an 
important development of the internationalisation practice and concept is underway, making it broader and more encompassing.

Examples from Danish and international universities. In the report "The Internationalisation of University Education"3 (Universitets- og Bygningsstyrelsen [UBST], 2007), it is specifically highlighted that internationalisation of higher education in Denmark is on its way into a new phase where

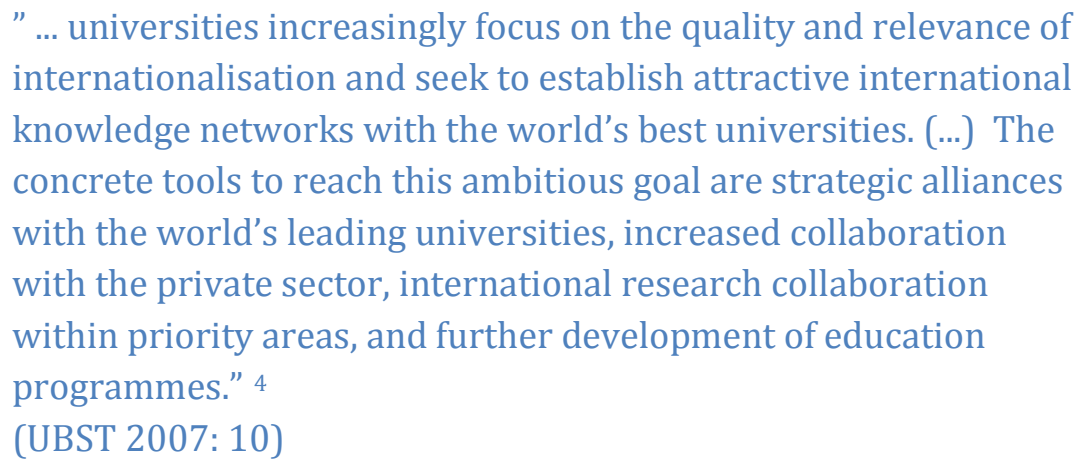

As was laid out in the previous section, this is a mirror of a broader international tendency. There are various examples of universities' ambitions in this direction and of actual activities to this end. With no intention of naming all of them, the following examples may illustrate the width of initiatives in Denmark and internationally.

Collaborative programmes. A number of Danish universities offer various forms of collaborative degrees or other types of education programmes that include a certain degree of inter-organisational collaboration. According to the UBST report (2007), several Danish universities participate in a so-called Erasmus Mundus consortium, through which European universities offer joint graduate degrees. At the time of the report, there were eleven Erasmus Mundus education programmes with Danish participation (UBST 2007: 7). Recently, the Danish Agency for International Education (IU) established that Danish universities participate in 23 Erasmus Mundus programmes, including nine approved in 2010 (IU: 2010). This indicates a steeply growing interest in the establishment of collaborative programmes with EU as well as global partners.

Another Danish example of collaborative activities involving non-European partners, but not established within the Erasmus Mundus programme, is the GLOBE programme at Copenhagen Business School (CBS), offered in collaboration with the Chinese University of Hong Kong and the KenanFlagler Business School at the University of North Carolina in the United States:

\footnotetext{
${ }^{3}$ The title is translated from Danish by the authors.

4 The quotation is translated from Danish by the authors.
} 


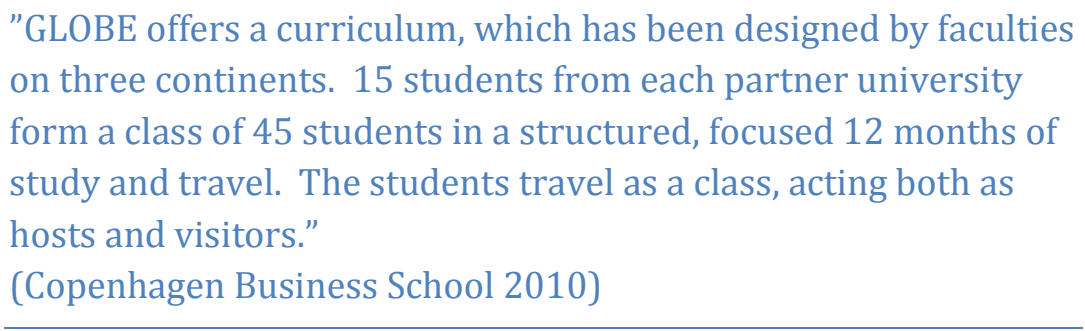

Before the physical mobility begins, students collaborate virtually on student projects (Copenhagen Business School 2010).

An international example is the recently established Global Master's in Development Practice (MDP), organised from Columbia University's Earth Institute in collaboration with 22 universities around the world: "The Global Master's in Development Practice (MDP) is a two-
year degree providing graduate-level students with the skills and
knowledge required to better identify and address the global
challenges of sustainability development, such as poverty, popu-
lation, health, conservation, climate change, and agricultural
productivity."
(MDP 2010)

Important stakeholders in the programme include John W. McArthur and Jeffrey Sachs, who in a recent article described part of the programme objective and experience as follows:

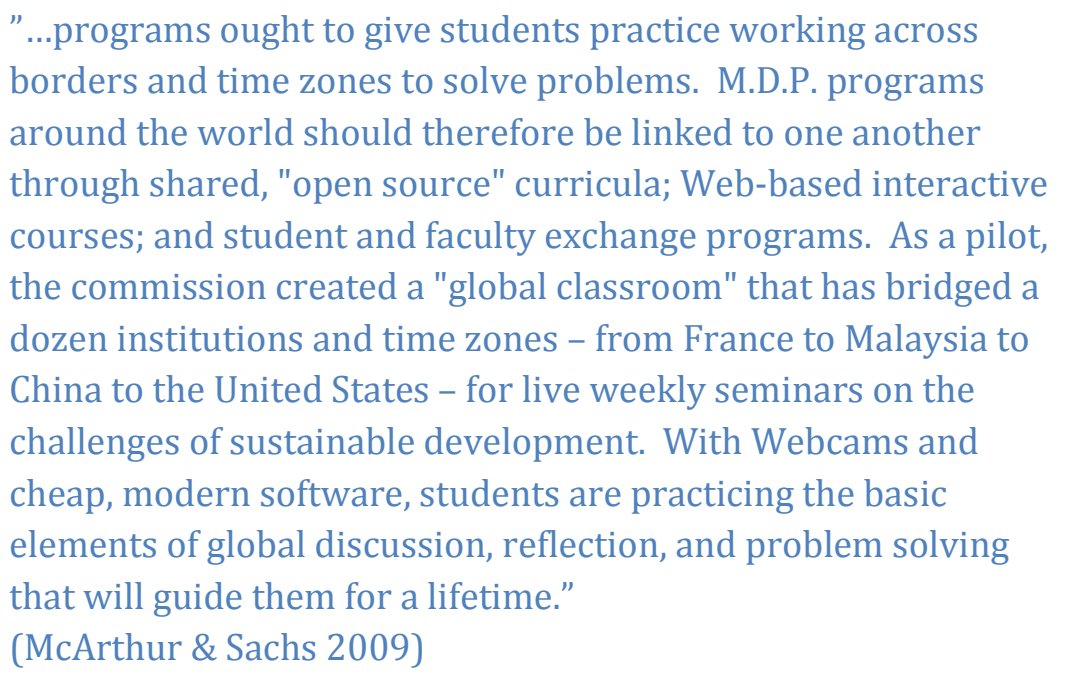

For a similar European endeavour, although within Management Education, interested readers can look at the CEMS community's Master of International Management (CEMS 2010). 
Entirely online. A Danish example showing a different focus but some of the same elements is the Climate Change course run at The University of Copenhagen's faculty of Life Sciences (LIFE). This course is offered as an entirely online course, developed by an international group of faculty situated in different locations, enrolling students from all over the world, all of them interacting in an entirely virtual class room. This is an example of an international experience where no-one necessarily goes abroad, but where students are still provided with an intercultural experience, which requires a high degree of intercultural competences (University of Copenhagen, 2010).

Internationally, a related example is the UK Open University (OU). OU is the largest university in the UK, dedicated entirely to distance education. OU offers undergraduate and graduate courses to over 225,000 students, 45,000 of which live outside the UK. The more than 450 different distance learning courses range from short online modules all the way through to the MBA and other master degrees. The University is ranked among the top five UK universities for teaching quality and top UK University for overall student satisfaction according to the National Student Survey 2009 and The Times (OU website 2010).

Collaborative projects. At the IT University of Copenhagen (ITU), the international perspective is a part of the overall strategy for the university. Thus the vision for the university reads:

\section{"...The IT University of Copenhagen is an outstanding example of how a small university can achieve a ranking among the best in the world, both in terms of academic standards and in terms of creating value, by being innovative and globally interactive." (ITU 2009)}

Global interaction is thus one of the primary means towards the end of delivering world class teaching and research. In practice, this is not merely about establishing a number of relevant partnerships with partners abroad. Global interaction is defined as a much more encompassing concept:

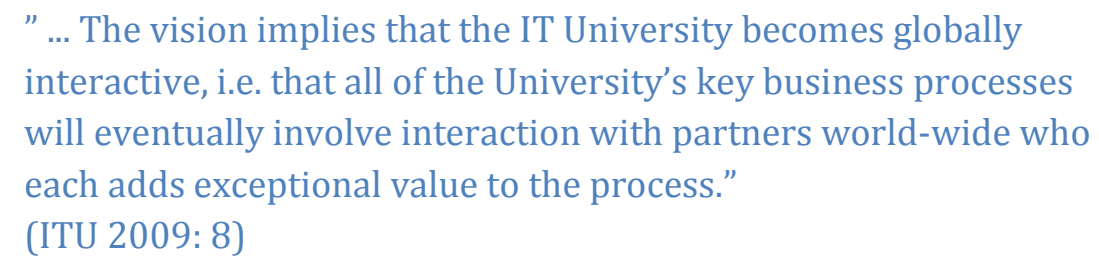

Such a vision is not achieved over night, but requires organisational change. Current pilot projects include for example two similar student collaboration projects, one with Peking University in China and one with 
Singapore Management University. The collaborations have a similar setup: student groups are formed by a mix of ITU students and students located at the partner university. They function as traditional project groups, working on a project together. However, collaboration between ITU and partner students is entirely distributed and technology mediated, students never meet physically, thus making this a good example of virtual mobility requiring the students to make creative use of various IT platforms and tools and manage a challenging, intercultural project process. Other pilot projects at ITU include among others: joint curriculum development, sharing of video and podcasts of lectures, and other collaborative projects with Georgia Institute of Technology in the United States.

Internationally, many similar examples of collaborative course and programme activities involving virtual mobility are carried out within numerous fields of study. A common denominator for many of them is that they, on top of the "normal" course learning goals, which are related to the field of study, have a stated objective of teaching students how to collaborate in a virtual setting by letting them collaborate virtually with costudents abroad. One example, particularly interesting because of its long history, is the Stanford based PBL ${ }^{5}$-lab, which has been running on a yearly basis since 1993. The aim of the course is to

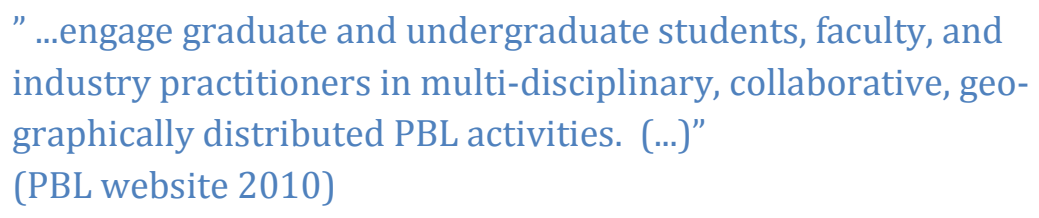

As stated on the website, their objective is to:

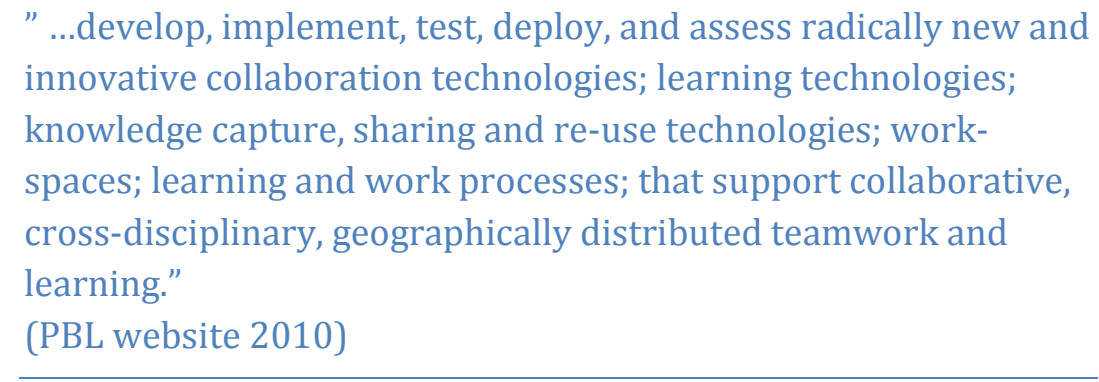

Students from many different universities around the world participate in the course from their remote locations. Other similar examples can be find in Bohemia \& Harman (2008), who describe both their own online collaborative course, and list a variety of other examples; also Cogburn \& Levinson (2003); Lago et al. (2008); Gan Kok Siew et al. (2010); Larsson et al. (2005) describe relevant examples.

\footnotetext{
${ }^{5} \mathrm{PBL}$ is a process of teaching and learning that focuses on problem-based, project-centered activities that produce a product for a client. (PBL website, 2010).
} 
Establishing presence abroad. A final Danish example worth mentioning is the establishment of a Danish University Centre in China. The project is a collaborative endeavour organised by all of the eight Danish Universities and the Graduate University of Chinese Academy of Sciences in unison. (Universities Denmark 2010). As such, it is a good example of the mobility of providers.

Internationally, there are numerous examples of the crossborder mobility of providers as mentioned in the previous section. An ambitious example is the endeavour of New York University (NYU) to become a 'global network university'. Towards this end NYU has recently established a remote campus in Abu Dhabi in the United Arab Emirates, which is to be a fully fledged research and teaching university - an extension of NYU in Manhattan. On the NYU website, the global network university idea is presented as follows:

"NYU has embarked on the project of becoming a Global Network University, a university that challenges the idea that a university can only deliver education at a single home campus. Instead, we have created a structure that allows students and faculty to gather in a set of key locales around the globe."

(NYU 2010a)

"Beyond NYU's portal campus in New York City lies a whole world of NYU global opportunity. With NYU Abu Dhabi, a new portal campus scheduled to open in 2010, and 10 international academic centers in Africa, Asia, Europe, North America, and South America, NYU offers global experiences to all members of its community."

(NYU 2010a)

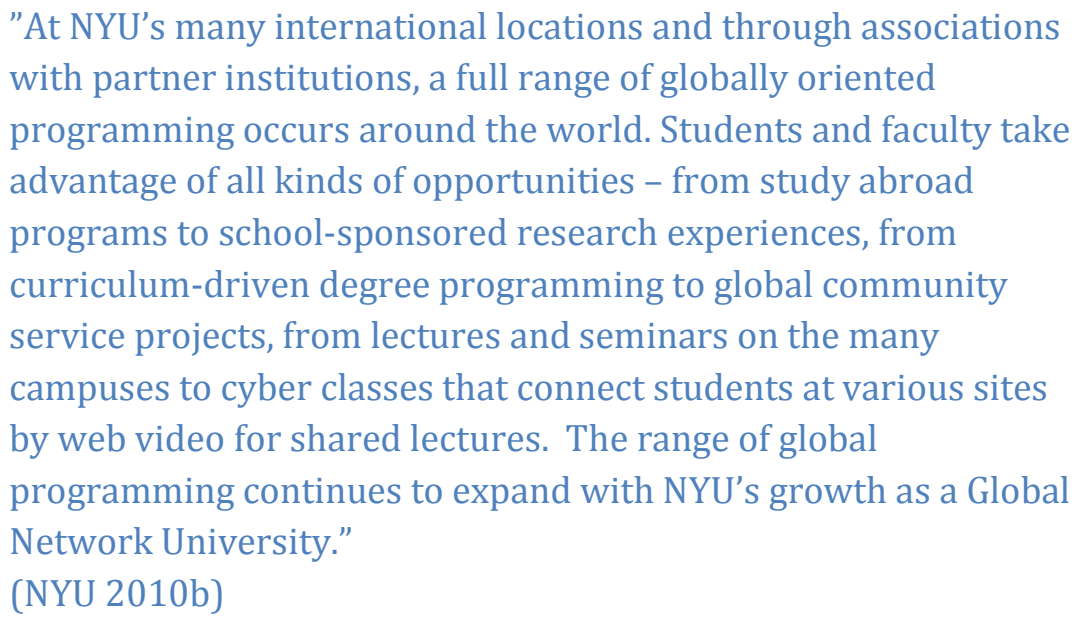


For numerous other examples of crossborder mobility of providers, see Knight 2008, Ch. 6.

\section{Internationalisation of higher education and the use of ICT}

What the cases show. The above overview of internationalisation tendencies and the Danish and international cases has shown that the concept and practice of internationalisation is developing and becoming broader and more encompassing. In the cases, we have also seen that ICTs are used for various purposes in many of these initiatives.

In terms of the increased mobility of people, we can see that the concept of virtual mobility of both students, faculty and also administrators play a role in many of the cases: the NYU's cyber classes connect students, faculty, and administrators across sites around the world to create the global network university; at ITU, LIFE, CBS, and OU students collaborate virtually with each other in different variations of distance education. In terms of the increased mobility of programmes, there is both the case of entirely online programmes that can be offered all over the world, as is the case with the OU programmes, but there is also the extensive development in international, collaborative programmes, where ICTs are used to support various activities, as is the case with the GLOBE Programme or the new MDP Programme. In terms of the increased mobility of providers, we can see that both LIFE, OU, and NYU use ICTs to a larger or smaller extent to enable their efforts to offer education abroad. In terms of the increased mobility of projects, we can see how ITU, and numerous other institutions of higher education around the world use ITCs to support for example course-based collaborations of both longer and shorter durations.

Finally, behind all of these initiatives lies an extensive administrative coordination across borders. Administrators, teachers, researchers, etc. distributed around the globe need to coordinate everything from programme and course activities, the technical set-up for a particular webconference, students' collaboration platforms, contracts and collaboration agreements, etc. This may seem trivial, but it is worth noting that the more or less smooth coordination of the increased mobility of all kinds relies heavily on ICTs.

Neither straightforward nor thoroughly explored. In spite of this picture, the connection between the internationalisation of higher education and the use of ICTs is neither straightforward nor thoroughly explored. As pointed out by Thune and Welle-Strand (2005), there are multiple assumptions, but actual studies investigating the connection in practice are few and far between. They argue that

"The literature on technology and internationalization is fragmented and chiefly occupied with conceptual issues. 


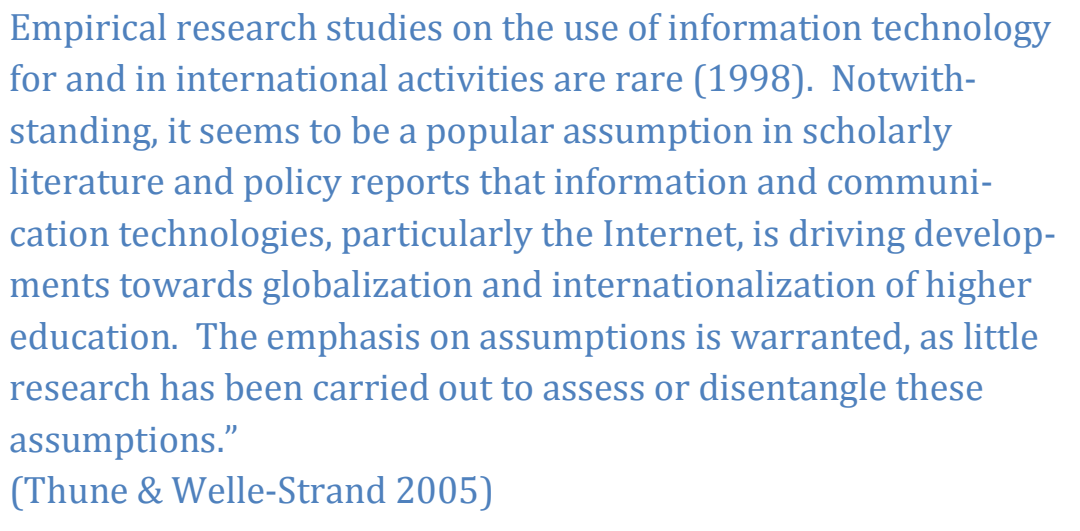

In reviewing the assumptions, Thune and Welle-Strand (2005) highlight three main functions of technology that are assumed to facilitate internationalisation: their ability to provide access to information and enable communication and interaction between people, irrespective of time and place. But as they argue:

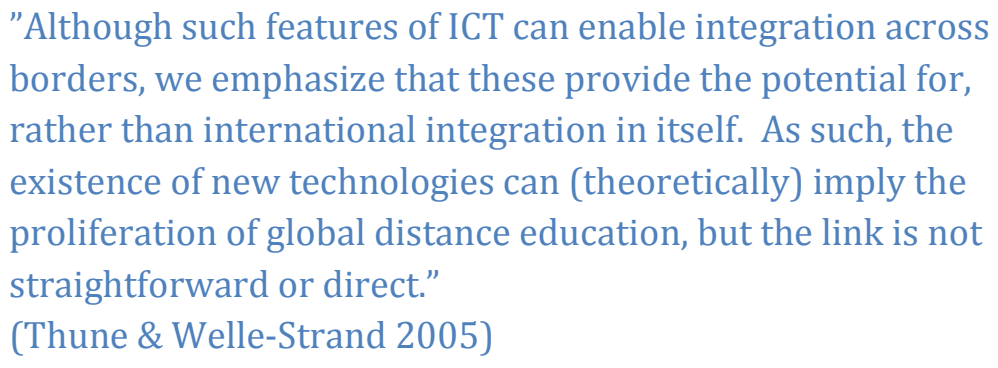

Based on the cases portrayed earlier in this paper, we claim that there are various practical examples of the creative use of technology to widen the concept and practice of internationalisation. Focusing on the three main categories of assumptions mentioned by Thune \& Welle-Strand (2005), the cases portrayed earlier in this paper show in various ways how ICTs are used particularly to provide access to information, and enable communication and interaction of people irrespective of time and place. As a matter of fact, these seem to be at the core of what ICTs are used for in many of the cases. We therefore claim that the potential for using ICTs to develop and broaden the internationalisation concept and practice is not merely an assumption, but can be verified in case examples both in Denmark and internationally. However, Thune and Welle-Strand (2005) have an important point in that the subject area is not thoroughly explored in research and empirical studies, and that the quantitative mass of initiatives does not seem overwhelming. This poses the question of why that may be so, and what may be important success criteria for using ICTs to broaden and develop internationalisation practice. 
Success criteria. Sarah Guri-Rosenblit (2001) explores current models and future trends of virtual universities with particular focus on the merits of ICTs in this context. She argues that:

"The promise of the new technologies in these multiple domains does exist, but their optimal and full actualization still remains a long way off. The author refers to three major problems hindering the efficient and effective use of the ICTs on a large scale: (i) the complex nature of these technologies; (ii) the associated costs of their differential uses; and (iii) the lack of systematic macro-level policies for their implementation in the many layers of institutional activities."

(Guri-Rosenblit 2001: 497)

She further explores this argument as follows:

"The complexity of the ICTs and the high costs associated with the processes of their implementation require a top-down macrolevel strategy for their effective utilization. Any serious shift of the existing learning infrastructures requires an overall institutional commitment, a gradual induction of both students and academic faculty to the new uses of the ICTs, the planning of appropriate support services, and clear financial prospects. (...) It seems that a combination of top-down and bottom-up elements appears to be the road to success in most cases of trying to design and implement policies in higher education on a macro level."

(Guri-Rosenblit 2001: 497)

Highlights are made by the authors of the present article).

With this quote, Guri-Rosenblit (2001) places herself within an overall academic discussion on the role and influential power of technology in society and within organisations. For a thorough review and analysis of this theme and the different points of view represented herein, interested readers may take a look at Boreham et al.'s New Technology @ work (2008). In summary, these authors - as Guri-Rosenblit (2001) - argue against technological determinism (i.e. the idea that technology determines the pace and content of social change), and stress the following basic view on the nature and role of technology in society and in organisations:

\footnotetext{
"Technology itself has no independent causal powers but it can make a significant difference to our working and other lives when it is invested with specific purposes by human agents (managers, policy makers) and is embedded in particular social
} 
relationships and institutions."

(Boreham et al. 2008)

In this article, we will not go into depth with this overall discussion on the role and nature of technology. Suffice it to say that it exists, and that naturally all answers to why ICTs are not used to a greater extent to develop and broaden internationalisation practices will depend on one's view on the basic nature and role of technology. We will follow Boreham et al. (2008) and Guri-Rosenblit (2001) and discuss what institutional factors may be important when attempting to use ICTs to further and develop internationalisation practices. The discussion will be based on practical experiences reported from LIFE as well as from recent working experience of the authors of this paper from the IT University of Copenhagen. To structure this discussion, we shall use Guri-Rosenblit's (2001) variables mentioned in the above quotes and relate them to practical experience in a Danish context.

Strategy \& institutional commitment. If the effective implementation of learning infrastructures in general require top down macro level strategies and institutional commitment to be implemented in any wider scale, which is the argument of Guri-Rosenblit (2001), it is not far off to assume that for ICTs to be used in internationalisation efforts, particularly in new and innovative ways that develop and broaden internationalisation practices, it requires a clear link to the internationalisation strategy and the institutional commitment to consistently follow up on that strategy and its ICT components.

For a number of years, The University of Copenhagen's faculty of life sciences (LIFE) has worked on establishing such a link between their internationalisation strategy and the use of ICT to develop and broaden their internationalisation efforts. Thus it is a stated part of their internationalisation strategy to focus on international distance education. In their action plan for internationalisation 2006-2008 it is stated that:

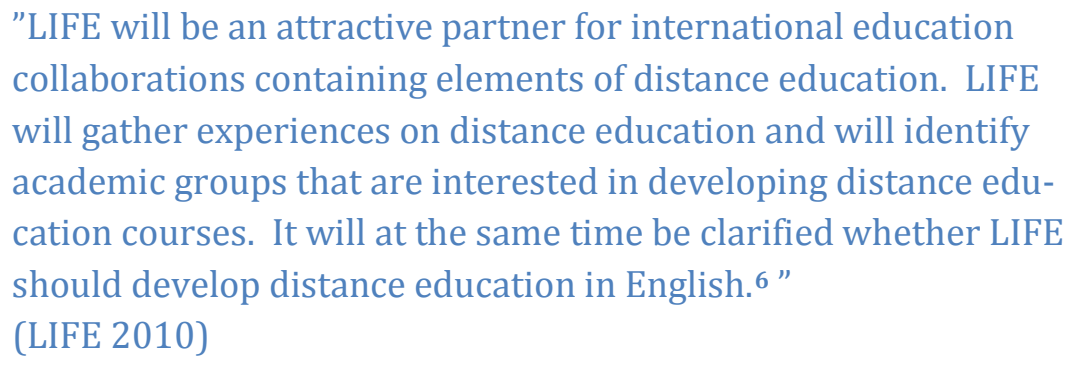
collaborations containing elements of distance education. LIFE will gather experiences on distance education and will identify academic groups that are interested in developing distance education courses. It will at the same time be clarified whether LIFE should develop distance education in English. ${ }^{\text {" }}$ (LIFE 2010)

\footnotetext{
${ }^{6}$ All quotes from the LIFE report have been translated from Danish by the authors.
} 
LIFE has already decided to do the latter, as was presented in the case of their online course offered in English to a group of students distributed all over the world.

It is explained in an analysis of the outcome of online courses at LIFE that one of the essential factors ensuring the success of their endeavours was the initial management support and the strategic anchoring of distance education as part of the internationalisation strategy. (IT Learning Centre 2010). More specifically, they conclude that:

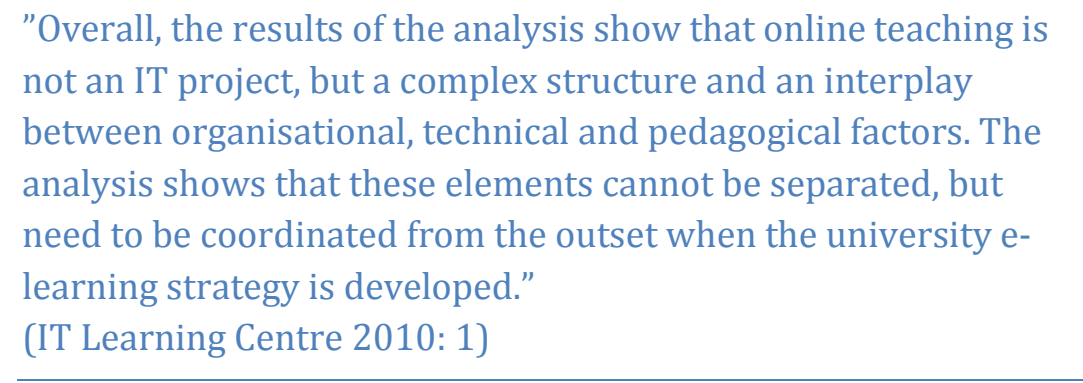

It follows that it also requires the use of ICTs to be anchored in the internationalisation strategy if there is a wish to further their use for this purpose - this adds another factor to the interplay and one more strategy that must be coordinated from the outset.

The importance of anchoring the use of ICTs for internationalisation purposes in the strategy has also been identified at ITU, where, as explained above, it is part of the overall vision of the university to be globally interactive and use ICTs to support and develop this interaction. Part of the institutional commitment to see this strategy through involves the continuous development of clear result goals related to the strategy, including a focus on the ICT infrastructure necessary to fulfil the strategy. In our experience, the overall management commitment to the strategy and the organisational pull that is created by having clear goals for the implementation of said strategy are crucial for creating ownership throughout the organisation for a process of change that is quite demanding of all parties involved. Without a strategy anchor and clear goals for implementation, the use of ICTs to develop and broaden internationalisation practice remains the projects of a few

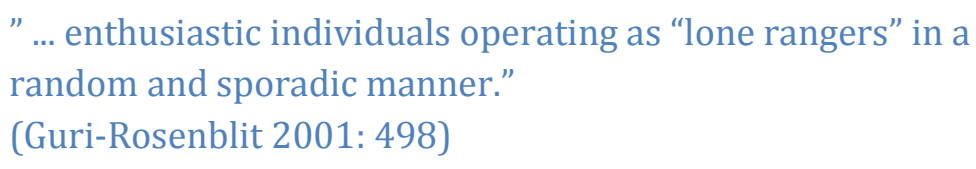

Support services. However, strategy and goals are not enough to ensure a broader use of ICTs in internationalisation activities. As pointed out by Guri-Rosenblit (2001), the right support services and infrastructure are 
crucial. This argument is supported by the LIFE report in which one of the conclusions is that:

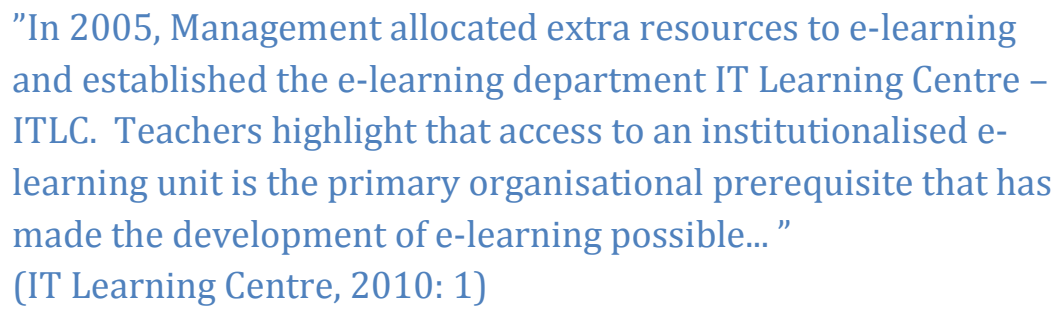

It follows from this that also the use of distance education as part of the internationalisation strategy and practice is heavily reliant on the e-learning support service.

Similarly, at ITU, a support unit, "Interaction \& Learning Unit", was established in 2008, uniting pedagogical support, e-learning support and support for developing globally interactive activities. Support activities are focused on the actual implementation of internationalisation practises, e.g. the teacher of a globally interactive course may need help with managing initial partner negotiations, pedagogical development of the course and relevant activities in a more or less unknown "virtual" setting, managing technical issues related to the use of ICTs for a particular activity in question; etc.

That the need for support is extensive is not surprising, since all parties involved are required to do something slightly different than usual, which presents challenges other than those they are used to and/or trained to manage. In fact, many of the challenges that have appeared during ITU's pilot experiments with planning and implementing virtual collaboration with partners abroad have closely resembled the challenges explained by Bohemia and Harman (2008) in their review of challenges faced by manufacturing companies attempting to shift from working in traditional colocated teams to geographically distributed virtual teams. They argue that design teams operating in distributed settings have experienced problems related to: long-term planning; lacking knowledge of current ICT tools; understanding how to share knowledge, ideas, documentation and materials; applying their interpersonal skills in the virtual setting; and weak intercultural communication abilities. (Bohemia \& Harman 2008: 60). Their argument is that

\footnotetext{
"The contemporary shift to the geographic distribution of design teams means that designers often require additional skills to those needed in more traditional workplaces. (...) Therefore it is timely that design educators begin developing curricula that introduce future engineers and industrial designers to elements
} 
of designing in a global context."

(Bohemia \& Harman 2008: 60-61)

Bohemia and Harman are focused on design education, since this is the topic of their article. However, their picture of modern organisations and the challenges they pose for their employees is also valid for other industries, and thus their point is also relevant in a more general educational setting. One can add to their argument, based on the experiences of ITU and the experiences reported by the LIFE report, that designing and implementing such educational programmes, including the ICT tools and their proper use, requires that the organisations administering the programmes engage in some internal learning and development of these new practices, which in turn requires proper support services and infrastructure.

Support services for development projects as complex as is the case with ICT enabled internationalisation efforts will rarely rely on one support unit/department. As visible from many of the examples presented above initiatives will usually involve different departments and groups at a university; e.g. International Office, the Study Administration, the ITdepartment, the Learning Unit, the Marketing Department etc. As such, there is an apparent need for coordination of involved faculty and technical/administrative support staff in order to get all departments across the organisation involved in the right way in the process of adopting and implementing new processes and practices and collaborate with each other in this pursuit. At ITU there is a well defined project governance model in place to ensure such cross-organisational cooperation, and it is our experience that some form of inter-organisational coordination is one of the most important prerequisites for implementing a broader and more encompassing internationalisation practice, including the use of ICTs for this purpose.

Top-down \& bottom-up. That top-down Management support and prioritisation is necessary is reflected in the above discussion about strategy. However, as Guri-Rosenblit (2001) argues, Management or external drive for a certain strategy is not enough, particularly not in a university setting, since

\footnotetext{
"...universities tend to fiercely resist any dictate from external forces, such as the government or any other central bodies. This reality is particularly evident in higher education systems in which the values of institutional autonomy and individual academic freedom are highly cherished." (Guri-Rosenblit 2001)
} 
At ITU, we have likewise experienced that the ownership and active participation of those who develop the academic programmes and the teachers who develop and teach individual courses is essential to the successful and academically relevant application of ICTs in internationalisation efforts. In order to avoid the type of resistance mentioned by Guri-Rosenblit above, a process is currently under way at ITU to ensure a relevant 'translation' of the overall strategy to academically and educationally relevant practices owned by employees - teachers, researchers, administrators, etc., and to ensure that the proper support is available throughout the process. Moreover, a defined working area of the supporting technical/administrative staff is to nurse any kind of strategically relevant bottom-up initiatives.

Clear financial prospects. Last but not least, Guri-Rosenblit (2001) points to clear financial prospects. That financial prospects and clear budgetary investments are important in order to reap the benefits of ICTs, also for internationalisation purposes, are important lessons from LIFE and ITU. One of the important success criteria highlighted in the LIFE report is the extra resources provided for the e-learning area (IT Learning Centre: 1). At ITU, the investment in a support function has also been prioritised, and questions of resources, incentives and business case are continuously discussed. Guri-Rosenblit (2001), with her focus on virtual universities and distance education, argues as follows:

"...the issue of costs is of tremendous importance in the distance
education context. Historically, distance education was justified
by its cost effectiveness and by its ability to provide economies of
scale. (...) If the new technologies do not lead to economies of
scale, and their effective implementation still requires larger
numbers of academic staff to be involved in the ongoing teaching
process, a paramount dilemma will face higher education institu-
tions: how to harness the information technologies in the frame-
work of their limited operating budgets?"
(Guri-Rosenblit 2001)

It follows from this picture that thinking through ones financial prospects of implementing a wider use of ICTs for any purpose, but perhaps particularly as a means to broaden and develop internationalisation practices, demands critical attention, since it is not given, and perhaps not even likely that economies of scale and an overall cost reduction will be a result of the efforts. At ITU, establishing the necessary ICT infrastructure and support services are seen as necessary investments in order to keep up with our overall vision of providing world class education and research. It is thus a strategic investment, and not done with the purpose of achieving a cost reduction. Other institutions may have other overall goals and purposes of using ICTs to broaden and develop their internationalisation prac- 
tices, but in either case it is important to link these to clear, transparent financial prospects.

\section{Concluding remarks}

In this article, we have explored the potential for using ICTs to develop and broaden the internationalisation practice and concept in higher education. We have established that the internationalisation concept and practice is currently developing and becoming broader and more encompassing as the mobility of people, programmes, providers and projects is increasing and diversifying. In various Danish and international cases we have seen how ICTs are being used in various attempts to broaden and develop internationalisation practices. However, the connection between internationalisation and the use of ICTs is not well established in research. Assumptions are numerous, but little evidence exists in the form of empirical studies, and research into the subject area seems to be scarce. That said, the cases show that many of the assumptions hold true in the sense that institutions of higher education do indeed use ICTs to develop and broaden the internationalisation concept and practices, although the quantitative weight of initiatives may be limited. Suggestions from research into virtual universities indicate that reasons for the limited quantity so far may relate to the complex nature of technologies, the associated costs of their differential uses, and the lack of systematic macro level policies for their implementation. It is also indicated that successful implementation requires overall institutional commitment on a strategic level, a process of both top-down drive and bottom-up ownership, proper support functions, and clear financial prospects and planning. These indications are supported by experiences from the Faculty of Life Sciences at The University of Copenhagen and the IT University of Copenhagen. However, these are merely the experiences of two smaller Danish institutions. Although they may serve as inspiration for other institutions and give some indications of important success criteria, there is an imminent need for more research in the area, not to mention more Danish-based and international experiments (and documentation of said experiments) on the use of ICTs to develop and broaden internationalisation practices.

\section{Referencer}

Bohemia, E. \& Harman, K. (2008) Globalization and Product Design Education: The Global Studio. Design Management Journal Vol. 3 No. 2.

Boreham, P., Parker, R., Thompson, P., Hall, R. (2008) New technology @ work. Routledge: London and New York.

CEMS website (2010) The global alliance in Management Education.

Retrieved on August 302010 from URL:

http://cems.org/general/index.php 
Cirius (2009) Mobilitetsstatistik for de videregående uddannelser 2007/2008. Retrieved from URL: http://www.iu.dk/publikationer/2009/mobilitetsstatistik-07-08

Cogburn, D. L., \& Levinson, N. S. (2003) U.S.-Africa Virtual Collaboration in Globalization Studies: Success Factors Complex, Cross-National Learning Teams. International Studies Perspectives, issue 4, pp. 34-51

Copenhagen Business School website (2010) The Globe Programme. Retrieved on February 252010 from URL: http://www.cbs.dk/uddannelser/bachelor/bacheloruddannelser/bsc in international business/menu/the globe programme/globe

Gan Kok Siew, B., Weinberg, R. \& Limam Mansar, S. (2010) Global Project Management: Pedagogy For Distributed Teams. In Z. Abas et al. (Eds.). Proceedings of Global Learn Asia Pacific 2010 (pp. 1408-1417). AACE.

Guri-Rosenblit, S. (2001) Virtual Universities: Current Models and Future Trends. Higher Education in Europe. Vol. XXVI, No. 4.

IT Learning Centre (2010) Analyse af udbyttet af onlinekurser på Det Biovidenskabelige Fakultet - LIFE, Københavns Universitet - KU. Developed for IT- og Telestyrelsen by IT Learning Centre at the Faculty for Life Sciences (LIFE), University of Copenhagen.

ITU IT University of Copenhagen (2009) The IT University of Copenhagen Strategy 2009-2011. Retrieved from URL:

http://www1.itu.dk/graphics/ITUlibrary/Internet/Ledelse/Strategidokumenter/2009-2011 strategi.pdf

IU Danish Agency for International Education website (2010) Dansk deltagelse i ni af årets Erasmus Mundus uddannelser. Retrieved on September 52010 from URL: http://www.iu.dk/nyheder/kortnyt/dansk-deltagelse-i-ni-af-aarets-erasmus-mundus-uddannelser

Knight, J. (2008) Higher education in turmoil: The changing world of internationalization. The Netherlands: Sense Publishers.

Lago, P., Muccini, H., and Babar, M.A. (2008). Developing a Course on Designing Software in Globally Distributed Teams. 2008 IEEE International Conference on Global Software Engineering.

Larsson, S., Boud, D., Dahlgren, M.A., Walters, S., and Sork, T. (2005) Confronting globalisation: learning from intercontinental collaboration. Innovations in Education and Teaching International, Vol. 42, No. 1, February, pp. 61-71.

LIFE website (2010) Handlingsplan 2006-2008. Retrieved on August 26 2010 from URL: 
http://www.life.ku.dk/om life/internationalisering/International/Han dlingsplan.aspx

Mason, R. (1998) Globalising Education. Trends and Applications. London: Routledge.

McArthur, J.W. \& Sachs, J. (2009) Needed: A new generation of problem solvers. The Chronicle of Higher Education, June 18, 2009. Retrieved on August 29 from URL: http://chronicle.com/article/Needed-ProblemSolvers/44512/

MDP website (2010) The Global Master's in Development Practice Programs Network. Retrieved on August 29, 2010 from URL: http://mdp.ei.columbia.edu/?id=home

Movinter Project website (2010a) Home. Welcome to Movinter. Retrieved on February 26th 2010 from URL: http://www.movinter.eu/

Movinter Project website (2010b) Presentation. What Movinter's concept of virtual mobility is based on. Retrieved on February 26 2010 from URL: http://www.movinter.eu/

NYU website (2010a) Global. Retrieved on August 292010 from URL: http://www.nyu.edu/global.html

NYU website (2010b) All NYU Programs. Retrieved on August 29, 2010 from URL: http://www.nyu.edu/global/all-nyu-programs.html

OU website (2010) UK Open University. Retrieved on August 29 from URL: http://www8.open.ac.uk/about/main/the-ou-explained

PBL website (2010) Problem project product process people based learning. Retrieved on August 312010 from URL: http://pbl.stanford.edu/

Styrelsen for internationale uddannelser website (2009) Bolognaprocessen. Retrieved from URL on January $28^{\text {th }} 2010$ : http://www.iu.dk/politiske-rammer/bologna-processen

Thune, T., \& Welle-Strand, A. (2005) ICT for and in internationalization processes: A business school case study, in Higher Education, Vol. 50, pp. 593-611.

Tinio, V.L. (2003) ICT in Education. UNDP-APDIP. Available at Wikibooks: http://en.wikibooks.org/wiki/ICT in Education

Universitets- og Bygningsstyrelsen (2007) Internationalisering af universitetsuddannelserne. Retrieved from URL: http://www.ubst.dk/publikationer/internationalisering-af- 
universitetsuddannelserne-marts-2007-1/internationalisering-afuniversitetsuddannelserne-marts-2007

Universities Denmark website (2010) Introduction to the Sino-Danish Centre of Education and Research. Retrieved on February 252010 from URL: http://dkuni.dk/politik debat/temaer/sdc english/

University of Copenhagen (2010) Course Information Faculty of Life Sciences. Climate Change Impacts, Adaptation and Mitigation. Retrieved on February 26th 2010 from URL: http://www.climate-change.dk/ 